\title{
Pollution control and energy advanced technologies
}

\author{
V. Himabindu ${ }^{1} \cdot$ P. Bhramara ${ }^{2}$
}

Received: 5 April 2016 / Accepted: 13 April 2016/Published online: 26 April 2016

(C) Springer-Verlag Berlin Heidelberg 2016

To sustain the growing human population, the natural resources have been manipulated to produce the materials in a non-sustainable way that threatens the very human existence.

Industrial revolution which begun with coal and oil as the primary fuel had not only assumed that there was no limit to the availability of these fuels, but also that their utilization will lead to any threat to our environmental health. Industries began manufacturing and using synthetic materials such as plastics, polychlorinated biphenyls (PCBs), and pesticides. These materials are toxic, non-biodegradable, and more important aspect is that they accumulate in the environment. Such actions had already caused severe loss of biodiversity, lack of access to safe drinking water, and health problems related to increased rates of cancers, physical birth defects, and mental retardation.

Governments of all nations need to prioritize environmental management efforts, including the implementation of multilateral environmental agreements and the provision of sustainable energy. This includes capacity building for the industrial sector as well as training in the adoption of the ecosystem approach and the sustainable use of its living resources. Innovative sustainable energy solutions are essential for making industries more productive and climate resilient.

Energy requirement has come a long way from the mere energy access to safe and reliable energy supplies to green and

Responsible editor: Philippe Garrigues

V. Himabindu

drvhimabindu@gmail.com

1 Centre for Environment, Institute of Science and Technology, Jawaharlal Nehru Technological University, Hyderabad, India

2 Department of Mechanical Engineering, College of Engineering, Jawaharlal Nehru Technological University, Hyderabad, India smart energy supplies. It has become a basic necessity, and energy utilization is an indicator of economic development of any nation. Thus, there is an urgent need for the development and use of sustainable energy options, as well as utilize the renewable energy to bridge the gap between energy demand and supply.

These inter-connecting and inter-depending aspects of environment and energy provide motivation to perform research in these fields with various challenges, observations, experimentation, and modeling at local, regional, and global levels and organize conferences in order to provide platform to discuss and interact over these issues.

Considering the importance of the environmental safety and clean energy, a 3-day international conference on Energy and Environment is being jointly organized by the Centre for Environment, IST, JNTUH, and Department of Mechanical Engineering, JNTUHCEH during 15th to 17 th of December 2014 at JNTUH, Hyderabad. In fact, the panel discussion conducted on the last day of the conference was very interactive, communicating with each other their experiences, achievements, and future prospects in this field and discussed the means to take these issues forward. Some of the salient outcomes of panel discussion are the following: (a) nanotechnology is observed to have a huge potential in the development of clean and efficient energy utilization and energy storage; (b) as wastewater treatment technologies are industry specific, it is necessary to offer tailor-made training programs on treatment of specific hazardous wastes with greater collaboration between industry and universities; (c) to encourage research on the study of impacts of climate changes on specific local areas of interest, adopting highresolution down-scaling methods with reference to socially relevant factors like rainfall, drought, health, and agriculture are to be encouraged; (d) regarding wastewater treatment, the major challenge is to treat complex effluent effectively. If the 
treatment starts at source for primary and secondary treatment, the tertiary treatment at a common area would be beneficial for the environment and (e) policy to be taken about MSW management whether to be taken by public department or private department.

The range of contributions in this special issue also reverberates the issues discussed in the panel discussion, viz., synthesis and characterization of nanomaterials, renewable energy production processes, energy from waste, and energy efficiency using nano- and green materials and processes. The editors are grateful to all the authors who invested time and effort in presenting their work in this issue, thus contributing towards environment and sustainable energy at large.

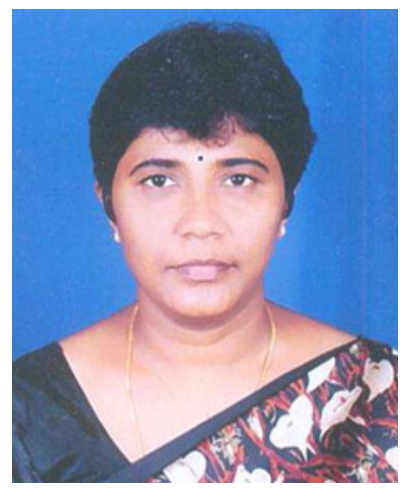

Dr. V. Himabindu She is an Associate Professor, Centre for Environment, and Co-ordinator, Centre for Alternative Energy Options, Centre for Environment, Institute of Science and Technology, Jawaharlal Nehru Technological University Hyderabad (JNTUH), India. She received $\mathrm{Ph}$. D in Chemistry from JNTU Hyderabad. She is the recipient of 17 research and development grants from the prestigious Indian Govt. and Private organizations. She has authored and

edited more than 120 peer-review articles.

Her research focuses on the monitoring of air, water, and soil pollutants and their control technologies, biofuel production, energy materials, sequestration of $\mathrm{CO}_{2}$ gases from industrial air emissions, and hydrogen energy. She serves as a reviewer for the repute international journals "Journal of Hazardous Material, Environmental Science and Pollution Research, International Journal of Hydrogen Energy, Journal of Water Process Engineering, Bioresource Technology, Int. J. of Environment and Sustainable Development."

She is a life member of the Indian Society for Technical Education and served as a member to the American Society of Civil engineers and recognized as approved analyst by Central Pollution Control Board, India. She developed in-house fabricated hydrogen production reactors through biological and chemical routes, chemical vapor deposition and flame reactors for nanomaterial synthesis, water, and wastewater treatment systems (conventional and advanced methods).

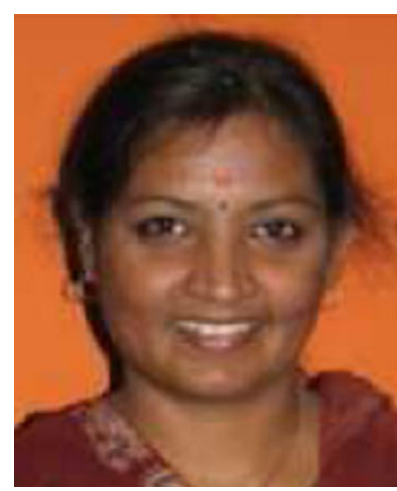

Dr. P. Bhramara She is presently working as an Associate Professor in the Department of Mechanical Engineering, JNTUH College of Engineering Hyderabad, India. She has 16 years of teaching experience. Her research publications are essentially in the field of modeling of two phase flows using CFD analysis in horizontal pipe, two phase heat transfer, nanofluids, and CFD analysis of squirrel cage fans for inlet parameters. She is the recipient of many research projects. 